\title{
ORIGINAL \\ THE PASSIVE CASE DETECTION OF MALARIA AT TEHSIL LIAQUETPUR
}

\author{
DR. ABDUL REHMAN, MBBS, DCH, FCPS \\ Consultant Paediatrician, \\ Tehsil Headquarter Hospital Liaquetpur
}

\begin{abstract}
Introduction: The purpose of this study is to compare the role of the doctors and the medical technicians/ dispensers in passive case detection (PCD) of malaria.Design: This is a non randomized clinical trial. Material and Methods: The PCD slides data of Malaria Control Programme Laboratory at Tehsil Headquarter Hospital Liaquetpur from 2001 to 2004 was divided into group A and Group B depending on whether the slides were advised by the doctors or the medical technicians/dispensers. $P$ value less than 0.05 was taken as significant. Results: The slide positivity rate (\%) of Group A vs. Group B was 17.11 vs. 5.64 ( $p<0.0001)$ in 2001, 9.35 vs. 3.17 ( $p<0.0001$ ) in 2002, 5.76 vs. 1.61 ( $p<0.0001$ ) in 2003 and 5.74 vs. 1.33 ( $p<0.0001$ ) in 2004. The falciparum rate (\%) of group A vs. group B was 2.59 vs. 0.46 ( $p<0.0001)$ in 2001, 2.06 vs. 1.15 ( $p=0.0342)$ in 2002, 0.3 vs. 00 ( $p=0.0767)$ in 2003 and 0.31 vs. 00 ( $p=0.1276$ ) in 2004. Conclusion: The performance of doctors group was better than those of medical technicians/dispensers group.
\end{abstract}

Key Words: $\quad$ Malaria, Passive Case Detection, Malaria Control Programme, slide positivity rate, falciparum rate, medical technician, doctor, dispenser.

\section{INTRODUCTION}

Malaria is a major public health problem in Pakistan. The geographical location of the country coupled with extensive agricultural practices, the world largest irrigation network causing water logging and monsoon rains have considerably added to the malariogenic potential of the area. The Malaria Eradication Programme in Pakistan was launched in 1960, which was later on, converted into Malaria Control Programme after its failure ${ }^{1}$.

The national targets of Malaria Control Programme are to reduce the annual incidence of malaria to a level less than 0.5 cases $/ 1000$ population, to keep the $P$.falciparum ratio below $40 \%$ of all malaria infections in the country and Passive Case Detection (PCD) should contribute more than $70 \%$ of all slides collected (2). The Passive Case Detection means diagnosis of malaria by blood smears in all cases of fever presenting to the health facility.

The purpose of this study is to compare the role of the doctors and the medical technicians and dispensers in Passive Case Detection of malaria.

\section{MATERIAL AND METHODS}

The Malaria Control Programme laboratory (for Tehsil Headquarter Hospital and for eight Basic Health Units in its surroundings) is situated at Tehsil Hospital Liaquetpur. The data of PCD slides from 2001 to 2004 
was collected from the laboratory record. There was no doctor posted at Basic Health Units due to shortage or unwillingness of doctors to stay there. The doctors at Tehsil Headquarter Hospital and the medical technicians/dispensers at Basic Health Units were responsible for patient checkup and advice for PCD slides.

The slides for malarial parasites were stained and examined following standard procedures by a qualified microscopist who had three month training in the concerned field of malaria. The characteristics of the population visiting to all these health facilities were nearly the same.
The data of PCD slides was divided into two groups, group $A$ the slides advised by the doctors and group $B$ the slides advised by the medical technicians and dispensers. GraphPad software programme was used for statistical purposes. Chi square test was applied where needed. $P$ value less than 0.05 was taken as significant.

\section{RESULTS}

The data from 2001 to 2004 was compared on yearly basis. Table-I shows the slide positivity rate, which was significantly higher with group $A$ as compared to group $B$. Table-II, shows the faciparum rate of both the groups.

\begin{tabular}{|c|c|c|c|c|c|c|c|}
\hline \multicolumn{8}{|c|}{ Table I. Slide positivity rate } \\
\hline \multirow[t]{2}{*}{ Years } & \multicolumn{3}{|c|}{ Group A } & \multicolumn{3}{|c|}{ Group B } & \multirow[t]{2}{*}{$P$ value } \\
\hline & Total slides & $\begin{array}{l}\text { Positive } \\
\text { Slides }\end{array}$ & $\begin{array}{l}\text { Slides positivity } \\
\text { rate }\end{array}$ & Total slides & $\begin{array}{l}\text { Positive } \\
\text { slides }\end{array}$ & $\begin{array}{l}\text { Slides positivity } \\
\text { rate }\end{array}$ & \\
\hline 2001 & 2314 & 396 & 17.11 & 2165 & 122 & 5.64 & $<0.0001$ \\
\hline 2002 & 2279 & 213 & 9.35 & 1481 & 47 & 3.17 & $<0.0001$ \\
\hline 2003 & 1685 & 97 & 5.76 & 1054 & 17 & 1.61 & $<0.0001$ \\
\hline 2004 & 976 & 56 & 5.74 & 754 & 10 & 1.33 & $<0.0001$ \\
\hline
\end{tabular}

\begin{tabular}{|c|c|c|c|c|c|c|c|}
\hline \multicolumn{8}{|c|}{ Table II. Falciparum rate } \\
\hline \multirow{2}{*}{ Year } & \multicolumn{3}{|c|}{ Group A } & \multicolumn{3}{|c|}{ Group B } & \multirow[t]{2}{*}{$P$ value } \\
\hline & Total slides & Positive slides & Falciparum rate & Total slides & Positive slides & $\begin{array}{l}\text { Falciparum } \\
\text { rate }\end{array}$ & \\
\hline 2001 & 2314 & 60 & 2.59 & 2185 & 10 & 0.46 & $<0.0001$ \\
\hline 2002 & 2279 & 47 & 2.06 & 1481 & 17 & 1.15 & 0.0342 \\
\hline 2003 & 1685 & 5 & 0.3 & 1054 & 0 & 00 & 0.0767 \\
\hline 2004 & 976 & 3 & 0.31 & 754 & 0 & 00 & 0.1276 \\
\hline
\end{tabular}

\section{DISCUSSION}

This is the first study in Pakistan comparing the role of doctors and other medical staff in Passive Case Detection of malaria. It showed that the performance of doctors was better than that of medical technicians/dispensers. There is a tendency of doctors to settle in cities due to lack of basic facilities in rural areas. As a result of which the role of medical technician/dispensers in the health of rural people cannot be ignored. The role of non-doctor health workers may be improved by given them training as proved by studies by Anand $\mathrm{K}$ et $\mathrm{al}^{3}$ and by Islam $\mathrm{A}^{4}$. WHO also recommended that the case detection and reporting systems needed review to improve passive case 
detection $^{2}$.

Further studies are needed in other areas of Pakistan to evaluate the performance of health workers in Malaria Control Programme.

\section{REFERENCES}

1. Report on Malaria Surveillance: Available from: http://www.emro.who.int/rbm/CountryReports/Pakistan Malaria Control Programme03.doc

2. Roll Back Malaria. WHO EMRO. Available from:
http://www.emro.who.int/rbm/AboutMalariaDeterminants.htm

3. Anand K, Patro BK, Paul E and Kapoor SK. Management of Sick Children by Health Workers in Ballabgarh: Lessons for Implementation of $\mathrm{IMCl}$ in India. J Trop Pediatr 2004; 50:41-47

4. Islam A, Malik F. Role of traditional birth attendants in improving reproductive health: lessons from the family health project, Sindh.J Pak Med Assoc 2001; 51:218-22.

\section{CONGRATULATIONS}

\section{Dr. Neaman Siddique}

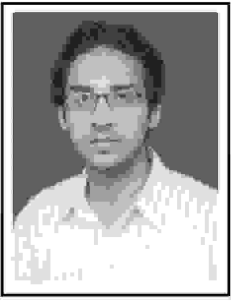

of Pathology department of Independent Medical College Faisalabad has been awarded "Sultan Farooqui Gold Medal" for securing highest marks in FCPS (Part-I) examination in the year of 2005.

\section{The Students, Staff \& Administration} of college wishes him Best of Luck 